\title{
BMJ Open Factors hindering the adherence to clinical practice guideline for diabetes mellitus in the Palestinian primary healthcare clinics: a qualitative study
}

\author{
Mahmoud Radwan, ${ }^{1,2}$ Ali Akbari Sari, ${ }^{1}$ Arash Rashidian, ${ }^{1}$ Amirhossein Takian, ${ }^{1,3}$ \\ Aymen Elsous, ${ }^{1}$ Sanaa Abou-Dagga ${ }^{4}$
}

To cite: Radwan M, Akbari Sari A, Rashidian A, et al. Factors hindering the adherence to clinical practice guideline for diabetes mellitus in the Palestinian primary healthcare clinics: a qualitative study. BMJ Open 2018;8:e21195. doi:10.1136/ bmjopen-2017-021195

- Prepublication history and additional material for this paper are available online. To view these files, please visit the journal online (http://dx.doi org/10.1136/bmjopen-2017021195).

Received 18 December 2017 Revised 3 August 2018 Accepted 21 August 2018

Check for updates

(C) Author(s) (or their employer(s)) 2018. Re-use permitted under CC BY-NC. No commercial re-use. See rights and permissions. Published by BMJ.

${ }^{1}$ Department of Health Management and Economics, School of Public Health, International Campus, Tehran University of Medical Sciences (IC-TUMS), Tehran, Iran ${ }^{2}$ International Cooperation Directorate, Palestinian Ministry of Health, Gaza Strip, Palestine ${ }^{3}$ Health Equity Research Centre (HERC), Tehran University of Medical Sciences (TUMS),

Tehran, Iran

${ }^{4}$ Department of Research Affairs and Graduates Studies, Islamic University of Gaza, Gaza Strip, Palestine

Correspondence to

Dr Mahmoud Radwan; mradwan78@hotmail.com

\section{ABSTRACT}

Objective Despite a high number of the internationally produced and implemented clinical guidelines, the adherence with them is still low in healthcare. This study aimed at exploring the perspectives and experiences of senior doctors and nurses towards the barriers of adherence to diabetes guideline.

Setting The Palestinian Primary Health Care-Ministry of Health (PHC-MoH) and Primary Health Care-United Nations Relief and Works Agency for Palestine Refugees in the Near East (PHC- UNRWA) in Gaza Strip.

Participants Individual face-to-face in-depth interviews were conducted with 20 senior doctors and nurses who were purposefully selected.

Methods Qualitative design was employed using the theoretical framework by Cabana et al to develop an interview guide. Semi-structural and audio-recorded interviews were conducted. Data were transcribed verbatim and thematically analysed.

Results The key theme barriers identified by participants that emerged from the analysed data were in regard of the PHC-MoH lack reimbursement, lack of resources and lack of the guideline trustworthiness, and in regard of PHCUNRWA the time constraints and the lack of the guideline trustworthiness. The two key subthemes elicited from the qualitative analysis were the outdated guideline and lack of auditing and feedback.

Conclusion The analysis identified a wide range of barriers against the adherence to diabetes guideline within the PHC-MoH and PHC-UNRWA. The environmental-related and guideline-related barriers were the most prominent factors influencing the guideline adherence. Our study can inform the policy makers and senior managers to develop a tailored interventions that can target the elicited barriers through a multifaceted implementation strategy.

\section{INTRODUCTION}

Diabetes mellitus (DM) is an increasingly serious public health issue targeted for action by world leaders. It is a major cause of blindness, kidney failure, heart attacks, stroke, lower limb amputation and can increase the overall risk of premature death and disability. ${ }^{1}$ The global prevalence of this epidemic is

\section{Strengths and limitations of this study}

- The strength of this study lies in the fact that it is the first qualitative study recruiting the framework by Cabana et al that has provided in-depth understanding of the factors hindering the adherence to the Palestinian diabetes guideline.

- Interviews explored determinants of adherence to diabetes guideline from different work settings and positions.

- Only the perspectives of senior doctors and nurses were included in this study. The views and perceptions of frontline professionals should be addressed in future studies.

- The other limitation is that we focused on barriers of adherence to the diabetes guideline as a whole rather than on its key recommendations.

increasing at an alarming rate. The International Diabetes Federation (IDF) estimates that, worldwide, about 425 million people aged 20-79 years have diabetes in 2017 with global prevalence of $8.8 \% .^{2}$ Approximately 4.0 million people aged between 20 and 79 years are estimated to die from diabetes in 2017, which is equivalent to one death every 8 s. Diabetes accounted for $10.7 \%$ of global all-cause mortality among people in this age group. $^{2}$ Over the past decade, diabetes prevalence has risen faster in low-income and middle-income countries than in high-income countries. In 2017, approximately 38.7 million people, or $9.6 \%$ of adults aged 20-79 years are living with diabetes in Middle East and North Africa. Diabetes is responsible for 318.036 regional deaths in adults aged 20-79 years in 2017 (13\% of all mortality). ${ }^{2}$

In Palestine, despite few epidemiological studies focused on the non-communicable diseases including diabetes, ${ }^{3}$ the IDF referred to some figures on DM. Most studies were cross-sectional in nature and provided 
estimates of the current prevalence for diabetes. In Gaza, getting valid and consistent estimates of diabetes prevalence over time seems to be difficult. A recent report by the United Nations for Relief and Works Agency for Palestine Refugees in the Near East (UNRWA) showed that the prevalence rate of diabetes was $15.9 \%$ in the West Bank and $12.9 \%$ in the Gaza among the registered Palestinian refugees aged 40 years and older. ${ }^{4}$ It has been projected that the prevalence of DM among Palestinians will be approximately $23.4 \%$ in $2030 .^{5}$

The Ministry of Health $(\mathrm{MoH})$ and UNRWA have developed guidelines, adapted to the Palestinian context, for the management of DM in accordance with the recommendations of relevant professional and academic international societies. ${ }^{3}$ Both guidelines are based on the WHO diabetes care guidelines. Despite a high number of the internationally produced and implemented Clinical Practice Guidelines (CPGs), the adherence with them is still low among healthcare workers. ${ }^{67} \mathrm{~A}$ common conceptual framework (Cabana et al) based on a systematic review on barriers to physician guideline adherence has been widely used. ${ }^{8}$ The framework encompasses three main barrier categories: knowledge-related barriers (lack of familiarity and lack of awareness); attitude-related barriers (lack of agreement, lack of self-efficacy, lack of outcome expectancy and lack of motivation/inertia of previous practice) and behaviour-related barriers (patient factors, guideline factors and environmental factors). It has been advocated to analyse the barriers influencing the guidelines adherence as an initially key step towards improving the adherence to guidelines. ${ }^{9}$ Based on the framework by Cabana et al, this study aimed at investigating the perspectives and experiences of senior doctors and nurses towards the main barriers of adherence to diabetes guideline in both the Palestinian Primary Health Care-MoH (PHC-MoH) and PHC-UNRWA.

\section{MATERIALS AND METHODS \\ Design}

Individual interviews with key informants from different key positions were done to explore their perceptions and experiences on the barriers of the adherence to diabetes guideline. A sample of 20 key informants (senior doctors and nurses) who were managing/supervising the functions related to chronic diseases at the $\mathrm{MoH}$ and UNRWA were purposefully selected.

\section{Qualitative data collection}

An interview guide was used that was developed based on the validated framework of Cabana $e t a l^{8}$ to standardise reporting of barriers. The choice of the framework by Cabana et al was based on the fact that it was the first framework developed to address the factors influencing guidelines adherence. In addition, the study by Cabana et al was based only on literature reviews that discussed doctors' adherence, while this is an empirical study based on qualitative research. Specific items of the
Cabana et al constructs (organisation constraints, lack of resources and lack of reimbursement) were tailored to match with the Palestinian local context.

A semi-structured interview approach was chosen in order provide more flexibility for both the participants and the researchers. ${ }^{10}$ This interview guide consisted of 16 open-ended questions assessing the importance of guidelines, guideline use, resources, guideline contents, issues in actual practice interfering with guideline use and suggestions for supportive measures (see online supplementary file).

The key informant interviews were conducted by the first author (MR). The interviewees were contacted faceto-face, and the average period time for the interviews ranged from 35 to $60 \mathrm{~min}$. At the beginning of each interview, participants were given a full briefing on the purpose of the study, the format of the session and issues of confidentiality.

\section{Sample size}

The key informants for the in-depth interviews were selected purposefully from different key positions. The snowball technique was used after identification of a set of potential key informants. The sample size was determined when saturation of themes was achieved. Regarding thematic saturation, 'the number of required subjects usually becomes obvious as the study progresses, as new categories, themes or explanations stop emerging from the data'. ${ }^{11}$ Thematic saturation in this study was achieved after conducting 20 individual interviews with no new themes appearing and themes repeating.

\section{Analysis approach of the qualitative data}

The interviews were audio-recorded, and data were transcribed verbatim to facilitate analysis. All transcriptions were carried out by a professional transcriptionist with master degree. There was no identification of participants' details during the transcription process. Participants were given a unique identifier to maintain anonymity, thus if on data analysis it is required to re-interview a particular participant, the code can be broken by the author and the participant can be re-contacted. The code was not broken in other circumstances and anonymity was preserved. The list of unique identifiers against names was kept on a secure file on the computer.

Data analysis consisted of developing a thematic framework, consisting of five steps of 'familiarisation', 'identifying a thematic framework', 'indexing', 'charting' and 'mapping and interpretation'. ${ }^{12}$ This method has been specifically developed for the analysis of qualitative data for policy-oriented studies.

\section{Stage 1: familiarisation}

The first author familiarised himself with all of the data through reading all the interview transcripts many times. A contact and content summary was developed for each interview. 
Stage 2: identifying a thematic framework

The first author went back through the summaries and listed the key notes/themes we had drawn-up at the familiarisation stage. A preliminary framework has been developed based on the model of adherence by Cabana et al, including the issues that were raised by interviewees. For those emergent issues that did not fit into the categories of the framework by Cabana et al, additional types of barriers were formulated.

\section{Stage 3: indexing}

All data were read and indexed (coded) according to the thematic framework. Indexing references were recorded in the margin of the transcript as a reference point. Sections of data were indexed with one or more codes (cross-indexing) wherever appropriate. The first author indexed the transcribed interviews with codes linked to the thematic framework. Then the coded texts were discussed with another PhD health policy researcher and coding was adjusted where appropriate. When necessary, a third researcher was consulted. This process was repeated several times for all the interviews. Indexing allowed us to organise the data and to explore ways in which topics were interlinked.

\section{Stage 4: charting}

We used thematic charting to build up a picture of the data as a whole. Data were lifted and rearranged in tables (Microsoft Excel) to enable us to look at experiences and issues across the data set, not just the transcribed interviews. We drew up charts for thematic analysis, where data for each theme were collected from all episodes of interview transcripts. Then we compared and investigated the views of each interviewee across different themes (looking across the rows) and the views of different interviewees about each theme (looking across the columns). We consulted the transcribed interviews and added extracts to the chart wherever necessary.

\section{Stage 5: mapping and interpretation}

Key themes which were developed from index points were then drawn together and mapped (subordinate themes into superordinate categories). The thematic framework was updated in the process of the analysis. This stage enabled us to define concepts, compare and contrast the perceptions or experiences, search for patterns and associations and explanations and develop strategies.

\section{Patient and public involvement}

Patients and/or public were not involved.

\section{RESULTS}

Twenty interviews were conducted (10 in the PHC-MoH and 10 in the PHC-UNRWA) among different senior positions (16 doctors and 4 nurses) (table 1 ). The themes elicited from this study were grouped according to the framework domains by Cabana et al (table 2). The major barriers identified were lack of reimbursement, lack of
Table 1 Demographic and clinical backgrounds of the interviewees

\begin{tabular}{|cc}
\hline Characteristics & $\begin{array}{l}\text { Number of participants } \\
(\mathbf{n = 2 0})\end{array}$ \\
\hline Age (years) & 9 \\
$40-50$ & 11 \\
$51-60$ & \\
Gender & 13 \\
\hline Male & 7 \\
\hline Female & \\
Work setting & 10 \\
\hline PHC-MoH & 10 \\
\hline PHC-UNRWA & \\
\hline Specialisation/position & 16 \\
\hline Senior doctor & 4 \\
\hline Senior nurse & \\
\hline Years of experience & 5 \\
\hline 10-15 & 15 \\
\hline 16 & \\
\hline
\end{tabular}

resources, lack of time and lack of guideline trustworthiness. The outdated guideline and lack of clinical audit and feedback (A\&F) most frequently emerged as subthemes. The lists within the subcategory were organised according to the more often identified.

\section{Environmental-related factors}

Environmental factors were the most prominent barrier related to behaviour of doctors and nurses in practising according to diabetes guideline. Particularly, lack of reimbursement, lack of resources, time constraints and lack of clinical A\&F were often reported as barriers to guideline adherence.

\section{Lack of reimbursement}

There was a general consensus among all interviewees in the $\mathrm{MoH}$ that the lack of incentives was a key barrier against the guideline adherence. Participants reported that the monetary incentives is totally absent. Some mentioned that the deteriorated political and economic condition in Palestine enforced the government towards freezing any decision related to payment system or job promotion. Many compared the monetary incentives of the UNRWA and the MoH, and believed that the UNRWA staff are more motivated due to the higher salaries. The participants in the UNRWA acknowledged that their staff receive salaries one and half time higher than their counterparts in the MoH. Moreover, they reported that the distinguished staff receive different kinds of incentives such as bonuses, annual awards or appreciation letters. Such incentives were rarely reported by the $\mathrm{MoH}$ interviewees. Surprisingly, the majority of the $\mathrm{MoH}$ interviewees argued that financial incentives appear to be the strongest barrier of guideline adherence. They defended 


\begin{tabular}{|c|c|c|}
\hline $\begin{array}{l}\text { Domain } \\
\text { framework }\end{array}$ & $\begin{array}{l}\text { Themes/subthemes } \\
\text { (barriers) }\end{array}$ & Codes \\
\hline \multirow[t]{4}{*}{$\begin{array}{l}\text { 1. Environmental- } \\
\text { related factors }\end{array}$} & Lack of reimbursement & $\begin{array}{l}\text { Financial incentives } \\
\text { Non-financial } \\
\text { incentives } \\
\text { Political-economic } \\
\text { condition }\end{array}$ \\
\hline & Lack of resources & $\begin{array}{l}\text { Material resources } \\
\text { Human resources } \\
\text { Limited budget }\end{array}$ \\
\hline & Lack of time & $\begin{array}{l}\text { Time pressure } \\
\text { Consultation time } \\
\text { Workload } \\
\text { Number of patients } \\
\text { seen }\end{array}$ \\
\hline & $\begin{array}{l}\text { Lack of clinical audit } \\
\text { and feedback }\end{array}$ & $\begin{array}{l}\text { Clinical supervision } \\
\text { Filed visit } \\
\text { Direct observation } \\
\text { File review } \\
\text { Clinical performance } \\
\text { Feedback }\end{array}$ \\
\hline \multirow[t]{2}{*}{$\begin{array}{l}\text { 2. Guideline- } \\
\text { related factors }\end{array}$} & $\begin{array}{l}\text { Guideline } \\
\text { trustworthiness }\end{array}$ & $\begin{array}{l}\text { Guideline evidence } \\
\text { Guideline content } \\
\text { Guideline } \\
\text { developers } \\
\text { Guideline } \\
\text { adaptation }\end{array}$ \\
\hline & Outdated guideline & $\begin{array}{l}\text { Latest evidences } \\
\text { Guideline lifespan } \\
\text { Updating process }\end{array}$ \\
\hline
\end{tabular}

such opinion by the view that in case of securing appropriate financial incentives, the professionals' behaviour might be broadly improved and consequently the likelihood of guideline adherence could be increased. Others expected that considering an appropriate financial scheme can effectively increase the competition and continuous professional development on guideline adherence.

...generally, most of the staff are frustrated due to the poor salaries and lack of incentive. How can they be committed to provide the care according to the guideline recommendations while they are demotivated... I can here say this proverb The one who does not have the thing, can't give it. (Senior doctor, $\mathrm{MoH})$

In our system, the personnel receive only fixed monthly salaries, no matter how many services they provide to patients. So there is no incentive for any additional tasks or for guideline adherence....unfortunately, the current salaries are quite hard to satisfy the nurse's needs. (Senior nurse, $\mathrm{MoH}$ )

The MoH interviewees stressed on the suggestion to review, perhaps to reform, the current payment system and link the monetary incentives to guideline adherence, particularly based on the quantity and quality of services provided to patients with diabetes.

\section{Lack of resources}

Lack of resources emerged as a central topic of concern in the $\mathrm{MoH}$ settings. All participants identified inadequacy of resources as principal barrier to the implementation of diabetes guideline. The participants discussed the need of resources as basic inputs that can lead to better processes and consequently to better adherence. They raised the issues of budget limitation and poor financial support to ensure the continuity of resources availability. Specific issues identified by participants included the frequent shortages in some drugs, laboratory kits and tests and nursing staff also. Although the UNRWA has its own stable finance route as a United Nations agency, few of interviewees expressed the need for more staff in order to effectively and appropriately apply the guideline recommendations. Some $\mathrm{MoH}$ participants described that the shortage of staff as an obstacle for implementation of the guideline.

...It is great to have diabetic guideline, but the lack of resources is a really challenging. How can doctors comply with the recommendation to do the HbAlc test three times yearly while the HbAlc kits are lacking or at least available with limited amounts... Alternatively, doctors use Fasting Blood Sugar which gives inaccurate findings in which many patients come to clinics with over-fasting state and this affects the results... So doctors are enforced to give inappropriate interventions. (Senior doctor, $\mathrm{MoH}$ )

A wide consistency across all the $\mathrm{MoH}$ participants in the suggestion of allocating a specific budget to secure the continuous availability of medicines and lab investigations for all chronic diseases and the diabetic patients in particular. A common suggestion elicited by the $\mathrm{MoH}$ and UNRWA participants was recruiting more doctors or nurses, and to hire more specialists such as endocrinologists, diabetes nurses, psychologists and dieticians.

\section{Time constraints}

The time constraints was highlighted as a significant barrier against the guideline adherence among participants in the UNRWA settings. Time factor was characterised by the view that there was inadequate time for implementing the guideline recommendations in a proper way. The majority of the participants claimed that many of professionals were enforced to shorten the consultation time due to the large number of daily patients seen. Some participants claimed that the consultation time with the UNRWA clinics is around $2.5 \mathrm{~min}$. They believed that such contact time is totally not enough, so they are in favour of increasing time to $4 \mathrm{~min}$ in average. Interestingly, the MoH interviewees admitted that the workload within the UNRWA clinics is heavier than the MoH due to the large number of patients seen in the UNRWA clinics. The UNRWA nurse participants also perceived the lack of 
time as a main challenge to be complied with the recommendations. They acknowledged that nurses find difficulties in properly assessing the patients, listening to their complaints or providing useful health education due to time constraint and increased workload.

...the doctors in the UNRWA see around 70-80 cases daily. It is not easy to provide a standardized care to all diabetic patients all the times. Sometimes we are enforced to give only 2-3 min for each patient, otherwise, other patients waiting outside might not be able to wait more...so they try to show their annoyance by knocking the office door many times... (Senior doctor, UNRWA)

...I think the full adherence to the diabetic guideline adds extra-burden on an already exhausted nurses... the nurses are overwhelmed with their routine assigned tasks... (Senior nurse, UNRWA)

A general suggestion was indicated by the UNRWA participants to scientifically analyse the workload across all the disciplines and accordingly reallocate the human resources. Another proposition was to make the current appointment system more restricted.

\section{Lack of clinical audit and feedback}

The lack of regular audit of performance was reported by the majority of the $\mathrm{MoH}$ interviewees to be a major barrier to guideline adherence. Some described the current monitoring as a non-systematically routine tasks done by an assigned supervisors. Others described it as an inspection mission enforced by the higher level in case of alarming errors. The participants admitted that even the feedback is limited to only providing some clinical comments that are rarely effective in changing the professional behaviour. The respondents argued that the inability to institutionalise the diabetic guideline into clinical routines was due to the lack of effective and wellplanned A\&F. Some of the participants suggested to use the most appropriate ways in using the feedback.

...Yes it can be said that we don't properly follow up our performance...often we rely on the monthly reports to monitor and measure the performance and achievement. (Senior doctor, $\mathrm{MoH}$ )

Some supervisors do their job in improper manner...they just try to detect errors and blame others. (Senior nurse, $\mathrm{MoH}$ )

Contrary to the situation in the $\mathrm{MoH}$, all the UNRWA key informants reported the clinical audit has been institutionalised in their system as a main function done by all the supervisory positions. They stated that they use various approaches for monitoring the guideline adherence such as field visit, direct observation, files auditing and the e-health programme.

As a bureaucratic system like the UNRWA, monitoring is one of the most prominent managerial function we do. We can say that we spend $15 \%$ of our time in monitoring. (Senior doctor, UNRWA)

\section{Guideline-related barriers \\ Guideline trustworthiness}

Discussion of credibility of the content of the diabetes guideline took an important part of the interviews, and revealed number of issues identified as important barriers to guideline adherence. Many doctors in both settings shared thoughts about the quality of evidence on which the guideline were based, which impacted the providers' adherence to the diabetes guideline. They claimed that the research evidence rigour were frequently not mentioned within the guideline itself. Although some of the interviewees had a trust in the guideline developers, they were not sure which methodology was used in developing the guideline or at least how the recommendations were finalised. The participants in the UNRWA reported that the development of their guidelines always performed externally with full reliance on the WHO guidelines. Many of the interviewees were familiar that the guideline developers adapted it according to the local context. They had a concern on such adaptation, which might be negatively affected by the content of the final recommendations. Despite the fact that this guideline was adapted from international guidelines as credible sources, some of the respondents believed that such adaptation was most likely to be deviated from the original evidences.

...Now the healthcare professionals are more aware about the meaning and the value of research evidence...during our meetings with them, they discuss the new evidences in diabetic care...they want to follow the international guidelines because of their credibility and originality... (Senior doctor, UNRWA)

\section{Outdated guideline}

One key subtheme barrier that was frequently raised by the majority of the interviewees in both settings was the outdated guideline. Some of them stated that more than eight years had passed since the last update of current diabetes guideline. Others claimed that some information or even recommendations were occasionally updated based on the needs and the availability of resources.

Some qualified doctors usually search in scientific websites and review the latest evidences in the treatment of diabetes, for example 'new antidiabetic medication', but unfortunately, they can't apply such evidence because it is not mentioned in the diabetic guideline. (Senior doctor, $\mathrm{MoH}$ )

...I do believe that the most factor hindering the UNRWA professionals from being adherent to guideline recommendations is the non-up-to-date guideline. (Senior doctor, UNRWA).

However, it has been repeatedly suggested by all the key informants to have a regular time period for updating 
the guideline; for instance, each 5 years at maximum. They also suggested forming a committee with specific responsibilities of regularly reviewing the updated research evidences relevant to the diabetes diagnosis and management.

\section{DISCUSSION}

\section{Summary of the results}

We performed a qualitative study and explored the main barriers influencing the adherence to diabetes guideline using the framework by Cabana et al. Our analysis proved that using the framework by Cabana et al was effective in identifying factors that most likely hindered the guidelines adherence. The analysis revealed a considerable variations in perceiving and experiencing the barriers of guideline adherence in the PHC-MoH and the PHC-UNRWA. The environmental-related and guideline-related barriers were the most prominent factors influencing the guideline adherence. The outdated guideline and the lack of A\&F were the two emerged subthemes.

\section{Comparison with the existing literature}

The main themes and subthemes that emerged from the analysed interviews with senior doctors and nurses are discussed below.

\section{Lack of reimbursement}

The $\mathrm{MoH}$ participants in the interviews intensively discussed the low salaries and its effects on the performance. They claimed that the lack of financial incentive was the strongest barrier against the guideline adherence. Despite the fact that monetary rewards can improve employee motivation and performance, ${ }^{13}$ they do not always produce desirable outcomes. Such finding might support a recently published study showing that the guideline adherence among UNRWA employees was low ${ }^{14}$ even though their monthly salaries were one time and half more than their counterparts in the MoH. In the $\mathrm{MoH}$, the average monthly salary of doctors and nurses was about US $\$ 1300$ and US\$800, respectively, while in UNRWA, it was about US $\$ 2000$ and US $\$ 1200$ for doctors and nurses, respectively. Such apparently inadequate salaries had not forced the governmental staff to engage in the private sector due to its limited scale in Gaza and lower wages as well. However, there are two possible explanations for the poor desirable outcomes of the financial incentives. First, high amounts of monetary incentives may lead to poor performance levels as a result of exaggerated increased fear of failure. ${ }^{15}$ Second, employees can develop a sense of entitlement to certain amounts of payment, ${ }^{16}$ otherwise, they can feel dissatisfied and have negative reactions if they do not get amount less than their expectations. ${ }^{17}$ A prominent suggestion by the $\mathrm{MoH}$ interviewees was to link the financial incentives with guideline adherence. This suggestion seems to be incomplete if compared with a study that provided recommendations on how to effectively use monetary rewards. ${ }^{18}$ One of the main suggestions is strongly link the monetary rewards with performance as much as possible, and not to irrelevant factors such number of years of work or indisputably following supervisor's instructions. ${ }^{19}$ Without a strong connection between pay and performance, employees are less likely to be motivated due to having doubt that increasing effort will result in additional pay. ${ }^{18}$ Another important suggestion is to use monetary and non-monetary rewards. The reason is that non-monetary rewards can motivate employees in ways rather than the monetary rewards do. ${ }^{13}$ For example, valuable training and development opportunities as rewards for good performance can motivate employees and increase their knowledge and skills. ${ }^{20}$ It appears that determination of the most influencing motivators on guideline adherence needs to be further studied and rigorously analysed.

\section{Lack of resources}

The MoH key informant interviewees cited lack of resources as a key barrier to the adherence of diabetes guideline. Shortages in staff and logistics such as medicines and lab tests were the most frequently mentioned. Notably, in a context like the Palestinian one where deteriorating political and economic situation is predominant, ensuring a continuous supply of medications and medical and laboratory consumables is really challenging. Due to the obvious financial limitation, most of these supplies come as donations. This sort of donation is often linked with donors' budget and priorities. In many low-income and middle-income countries (LMICs), the medical resources are insufficient and the basic services are often unavailable. ${ }^{21} \mathrm{WHO}$ estimates that the average availability of essential drugs in LMICs is $35 \%$ in public sector facilities and $66 \%$ in the private sector. ${ }^{22}$ In the Palestinian healthcare system, it seems that tackling the issue of irrational medicine use is considered to be quite essential to allow for optimal utilisation of scarce resources and to improve healthcare delivery. Reinforcing the rational use of medicines requires effective policies as well as adequate collaboration between healthcare professionals, patients and entire communities. ${ }^{23}$ Although the lack of resources is extremely challenging in the Palestinian context, the decision makers are strongly invited to judge the most efficient ways for rational use of the scarce resources. ${ }^{24}$

\section{Lack of clinical audit and feedback}

A first key subtheme expressed by the MoH key informants was the lack of A\&F in which many of them thought it was a barrier against the guideline adherence. This finding could be attributed to the view that the supervision concepts were generally lacking in the $\mathrm{MoH}$ health facilities and mostly focused on detecting errors and blaming employees rather than providing coaching, support and training. ${ }^{25}$ In guidelines implementation, A\&F has been used to increase guideline adherence in many different settings and conditions. ${ }^{26-28}$ Several studies including a meta-analysis pointed out that the audited health services have exhibited significant positive effect 
compared with those services without auditing. ${ }^{29-31}$ In the same time, systematic reviews indicated that the effect of A\&F is generally modest in improving performance. ${ }^{32} 33$ However, it seems that the effectiveness of A\&F depends on baseline performance and how the feedback is provided. ${ }^{33}$ Ivers et al in their systematic review concluded that the 'feedback may be more effective when baseline performance is low, it is provided more than once, it is delivered in both verbal and written formats, the source is a supervisor or colleague and when it includes both explicit targets and an action plan' ${ }^{33}$ It appears sensible to suggest that the efforts to change the MoH provider practice should be targeted at behaviours for which there is evidence supporting the most appropriate practices of $\mathrm{A} \& \mathrm{~F}$ in order to enhance the guideline adherence.

\section{Time constraints}

Time constraints with a heavy workload were qualitatively perceived as a major barrier to guideline adherence among UNRWA participants. They simply felt that there was not enough time to deliver the diabetic care according to the guideline recommendations. Similar result revealed the majority of the key informants reported that the main barriers that prevented them from adhering to guideline recommendations of diabetes and hypertension were the time constraints and increased workload..$^{34}$ Higher provider workloads have potentially negative impact on patients' quality of care, ${ }^{35}$ patient satisfaction $^{36}$ and job satisfaction. ${ }^{37}$ Time constraints largely increase with higher workloads. An experimental study pointed out that time pressure enforced the general practitioners to partially follow the guideline (eg, conducting limited clinical examination, asking significantly less clinical questions and providing less advice on lifestyle). ${ }^{38}$ The UNRWA participants claimed that many professionals were enforced to shorten the consultation time to around $2.5 \mathrm{~min}$ due to the large numbers of daily patients seen. A recently systematic review found that average consultation length differed across the world, ranging from $1.7 \mathrm{~min}$ in Pakistan, $7.1 \mathrm{~min}$ in Egypt, $6.9 \mathrm{~min}$ in Iran, $8.2 \mathrm{~min}$ in Turkey, $21 \mathrm{~min}$ in the USA to $22.5 \mathrm{~min}$ in Sweden. ${ }^{39}$ The review concluded that short consultation length is likely to adversely affect patient healthcare and physician workload and stress, ${ }^{39}$ as well reduce the range of services provided in primary care. ${ }^{40} 41$ Therefore, it could be highly suggested that the issuing of guidelines should be preceded by workload analysis studies so that barriers to the implementation are minimised. In this regard, extra efforts might be done to implement more structured procedures such as recruiting adequate numbers of professionals and giving of specific appointment times to individual patients.

\section{Lack of guideline trustworthiness}

In both settings (PHC-MoH and PHC-UNRWA), most of the interviewees expressed clear concern on the credibility and quality of the evidences on which the guidelines were based. This finding was supported by a recent study that assessed the methodological quality of the current diabetic guideline using the Appraisal of Guidelines, Research and Evaluation (AGREE) II instrument and revealed that its rigour of evidences was low. ${ }^{42}$ Previous studies showed that adherence to recommendations based on scientific evidence is higher than the recommendations that are not supported with evidence. ${ }^{434}$ Guideline recommendations should always be accompanied by a systematically derived summary of best available evidence that rates evidence quality and links it with the strength of recommendations, ideally using the Grading of Recommendations Assessment, Development and Evaluation (GRADE) system. ${ }^{45}$ The GRADE approach provides 'a comprehensive, explicit and transparent methodology for grading the quality of evidence and strength of recommendations about the management of patients' ${ }^{46}$ Surprisingly, even the WHO recommendations are often inconsistent with GRADE guidance, partly due to shortcomings in their understanding of GRADE. ${ }^{47}$ Ensuring optimal application of GRADE at WHO and elsewhere likely requires further training in GRADE methods for guideline development of group members.

Another striking point raised by many of the key informants was on their concerns that the guideline adaptation and forming the final recommendations were most likely to be deviated from the original evidences. Similarly, a recent study pointed out that the Indonesian diabetes guideline which was adapted from international guidelines lacks the transparency in adaptation. ${ }^{48}$ However, most of the guidelines in LMICs are adapted from pre-existing international guidelines. A recent systematic review on diabetes guidelines in non $\square$ Western countries found that $79 \%$ of the guidelines were based on recommendations from other national or international guidelines. ${ }^{49}$ Several studies revealed that there are considerable variations and even conflicting recommendations concerning type 2DM management from different guidelines. ${ }^{50} 51$ Implementation of evidence $\square$ based practice criteria such as those proposed by ADAPTE collaboration should be followed when guideline is derived from other guidelines to be used in different context. ${ }^{48}$ Instead of developing new guidelines, the ADAPTE collaboration was established to develop a stepwise and systematic approach to improve efficiency of guideline development, reduce duplication of efforts and produce valid and high-quality guidelines that are relevant for use in a local context. ${ }^{52} 53$

\section{Outdated guideline}

A second key subtheme elicited from the analysed interviews in both settings (MoH and UNRWA) was the outdated guideline. It appears that neither the guideline expiration date nor the systematic updating process was considered. Most organisations do not have formal procedures for updating their guidelines. ${ }^{54}$ An international survey found that half of the organisations do not have a formal process to determine when a guideline becomes invalid. ${ }^{55}$ A systematic review of 35 methodological handbooks for better updating process of guidelines found 
that generally the updating process is poorly prescribed. ${ }^{56}$ Shekelle $e t$ al analysed the validity of a cohort of guidelines and indicated that $90 \%$ of guidelines were still valid in 3.6 years, but $50 \%$ were outdated in 5.8 years. ${ }^{57}$ However, there is no fixed lifespan for a guideline, an update every $3-5$ years is generally recommended. ${ }^{55}$ 57-59 Various studies have consistently identified common difficulties in updating guidelines; lack of standardised time for guideline updating, lack of standardised and rigorous process for updating, lack of efficient review system to identify recent and relevant evidence; decisions on partial or full updating and the cost-effectiveness of updating a guideline..$^{55} 50$ It can be suggested that the guideline developers should determine a time period for updating, and provide more explicit formal procedures of updating the diabetes guideline in order to assure guideline validity.

\section{Strengths and limitations}

The strength of this study lies in the fact that it is the first qualitative study recruiting the framework by Cabana et al that has provided in-depth understanding of the factors hindering the adherence to the Palestinian diabetes guideline. Interviews explored determinants of adherence to diabetes guideline from different work settings and positions through a careful selection of the study sample in order to help in transferability of findings. Maximum variation is a sampling method which is likely to allow for the application of the study to a wider audience. ${ }^{10}$ Participants were contacted (member checks) to confirm the researchers' guesses or feelings related to the transcripts. The researcher's experience and background in quality improvement and practice guidelines enabled him to understand the meaning of some interview responses that might have been difficult to understand otherwise. Each transcript was checked several times against the digital recording from which it had been made. In the data analysis stage, the researcher analysed the data in each transcript independently with a $\mathrm{PhD}$ researcher of health policy and in case of any discrepancies, a consensual conclusion about the codes and themes was arrived at after consulting a third expert and the local academic advisor. A limitation of this study was that only the perspectives of senior doctors and nurses were included in this study. The views and perceptions of frontline professionals should be addressed in future studies. The other limitation is that we focused on barriers of adherence to the diabetes guideline as a whole rather than on its key recommendations.

\section{Implications for policy and practice}

The following points are suggested recommendations and policy implications:

- Multifaceted implementation strategies targeting the main barriers elicited from this study are extremely required for addressing the knowledge, incentives, organisational resources, the rigour of guideline development and time constraints. Recent evidence concluded that a tailored implementation strategy targeting perceived barriers is useful for improving the guideline adherence. ${ }^{61}$

- To improve the quality of our current and future guidelines, a systematic and rigorous approach in synthesis of guideline recommendations is extremely advised. The AGREE II instrument should be incorporated as a gold standard for developing, evaluating or updating the Palestinian CPGs. Instruments like AGREE II, GRADE and Preferred Reporting Items for Systematic Reviews and Meta-Analyses could be quite useful tools and contribute positively in the improvement of guidelines quality and transparency.

- It seems sensible to deeply analyse what could motivate the Palestinian healthcare professionals prior to any guideline implementation. Hence, the Palestinian national payment method and the incentive scheme should be carefully reviewed and redesigned taking into account the monetary and non-monetary incentives.

- Although insufficient resources is extremely challenging in the Palestinian context, the decision makers are strongly invited to judge the most efficient ways for rational use of the scarce resources.

- Workload analysis studies are highly demanded prior to any potential development of clinical guidelines.

- For future research, the framework by Caban $e t$ al should be tested alongside randomised trials to test the causal factors of guideline adherence/ non-adherence.

\section{CONCLUSION}

To the best of our knowledge, this is the first study using the framework by Cabana et al to investigate the main barriers influencing the adherence to diabetes guideline. Our analysis proved that using the framework by Cabana $e t$ al was effective in identifying factors that most likely impeded the guidelines adherence. The analysis identified a wide range of barriers against the adherence to guideline for DM within the PHC-MoH and PHC-UNRWA. The environmental-related and guideline-related barriers were the most prominent factors influencing the guideline adherence. In the PHC-MoH, the most perceived barriers to guideline adherence were lack of reimbursement, lack of resources and lack of the guideline trustworthiness, whereas the time constraints and the lack of the guideline trustworthiness were the most prominent barriers in the PHC-UNRWA. The two key subthemes elicited from the qualitative analysis were the outdated guideline and the lack of A\&F. The results of this study can help in explaining why doctors and nurses in both settings do not adhere to diabetes guideline. Our study can inform the policy makers and senior managers to develop a tailored intervention that can target the elicited barriers through a multifaceted implementation strategy.

Acknowledgements The authors would like to thank all the interviewees. The authors would also like to thank the transcriptionist Taghreed Al-Ghoti. 
Contributors All authors have contributed significantly in this research work. The authors (MR, AAS, AR, AT) significantly contributed in the study design and the critical review of the manuscript. The principal investigator (MR) collected, analysed, interpreted the data and wrote the first draft of the manuscript. The authors (SA-D, AE) highly contributed in the analysis and interpretation of data. Final approval was given by all authors.

Funding The authors have not declared a specific grant for this research from any funding agency in the public, commercial or not-for-profit sectors.

Competing interests None declared.

Patient consent Not required.

Ethics approval Ethical approval has been obtained from ethical approval committee in Gaza, and administrative approvals from the PHC-MoH, PHC-UNRWA. Verbal consent has been obtained from all interviewees to participate after giving them brief explanations about the purpose of the study. The study participants were informed about their right to participate or not to participate in the study.

Provenance and peer review Not commissioned; externally peer reviewed.

Data sharing statement The interview guide is available from the first author on request.

Open access This is an open access article distributed in accordance with the Creative Commons Attribution Non Commercial (CC BY-NC 4.0) license, which permits others to distribute, remix, adapt, build upon this work non-commercially, and license their derivative works on different terms, provided the original work is properly cited, appropriate credit is given, any changes made indicated, and the use is non-commercial. See: http://creativecommons.org/licenses/by-nc/4.0/.

\section{REFERENCES}

1. WHO. Global report on diabetes. Geneva: World Health Organization, 2016.

2. IDF. IDF, Diabetic atlas. 8th edn. Brussels, Belgium: International Diabetes Federation, 2017.

3. Husseini A, Abu-Rmeileh NM, Mikki N, et al. Cardiovascular diseases, diabetes mellitus, and cancer in the occupied Palestinian territory. Lancet 2009;373:1041-9.

4. UNRWA, 2017. Annual report of the department of health. United Nations Relief and Works Agency for Palestine refugees in the Near East Amman, Jordan https://unispal.un.org/DPA/DPR/unispal.nsf/0/ AA762998019FAB0E8525812C004FBCE6

5. Abu-Rmeileh NME, Husseini A, O'Flaherty M, et al. Forecasting prevalence of type 2 diabetes mellitus in Palestinians to 2030: validation of a predictive model. The Lancet 2012;380:S21.

6. Hepner KA, Rowe M, Rost K, et al. The effect of adherence to practice guidelines on depression outcomes. Ann Intern Med 2007:147:320-9.

7. Kennedy PJ, Leathley CM, Hughes CF. Clinical practice variation. Med J Aust 2010;193:S97-9.

8. Cabana MD, Rand CS, Powe NR, et al. Why don't physicians follow clinical practice guidelines? A framework for improvement. JAMA 1999;282:1458-65.

9. Grol R, Grimshaw J. From best evidence to best practice: effective implementation of change in patients' care. Lancet 2003;362:1225-30.

10. Merriam S. Qualitative research: a guide to design and implementation. San Francisco: Jossey-Bass, 2009

11. Marshall MN. Sampling for qualitative research. Fam Pract 1996;13:522-6.

12. Ritchie J, Spencer L. Qualitative data analysis for applied policy research. Analysing qualitative data. London: Routledge, 1994:173-94.

13. Long RJ, Shields JL. From pay to praise? Non-cash employee recognition in Canadian and Australian firms. Intern J Hum Resour Manag 2010;21:1145-72.

14. Radwan M, Akbari Sari A, Rashidian A et al. Attitudes of Palestinian health-care professionals in Gaza to clinical practice guideline for diagnosis and treatment of diabetes mellitus. Front Endocrinol 2017;8:288

15. Chib VS, De Martino B, Shimojo S, et al. Neural mechanisms underlying paradoxical performance for monetary incentives are driven by loss aversion. Neuron 2012;74:582-94

16. Beer M, Cannon MD, Baron JN, et al. Promise and peril in implementing pay-for-performance. Hum Resour Manage 2004;43:3-48.
17. Schaubroeck J, Shaw JD, Duffy MK, et al. An under-met and overmet expectations model of employee reactions to merit raises. $J$ Appl Psychol 2008;93:424-34.

18. Aguinis $\mathrm{H}$, Joo H, Gottfredson RK. What monetary rewards can and cannot do: How to show employees the money. Bus Horiz 2013;56:241-9.

19. Trevor CO, Reilly G, Gerhart B. Reconsidering pay dispersion's effect on the performance of interdependent work: reconciling sorting and pay inequality. Acad Manage J 2012;55:585-610.

20. Brown S. Training and employee development for improved performance. Zedeck S, ed. APA handbook of industrial and organizational psychology. Washington, DC: American Psychological Association, 2011;2:469-503.

21. Maitland K. Management of severe paediatric malaria in resourcelimited settings. BMC Med 2015;13:42.

22. Leisinger KM, Garabedian LF, Wagner AK. Improving access to medicines in low and middle income countries: corporate responsibilities in context. South Med Rev 2012;5:3-8

23. Almarsdóttir AB, Traulsen JM. Rational use of medicines--an important issue in pharmaceutical policy. Pharm World Sci 2005;27:76-80.

24. Grimshaw JM, Thomas RE, MacLennan G, et al. Effectiveness and efficiency of guideline dissemination and implementation strategies. Health Technol Assess 2004;8:1-72.

25. PNGO. Priorities and Needs of Health Sector in Gaza Governorates: consequences of the long Siege and the last war on Gaza. Gaza, Palestine: Palestinian Non-Governmental Organizations Network, 2009.

26. Harvey PA, Murphy MC, Dornom E, et al. Implementing evidencebased guidelines:inpatient management of chronic obstructive pulmonary disease. Intern Med J 2005;35:151-5.

27. Baker R, Falconer Smith J, Lambert PC. Randomised controlled trial of the effectiveness of feedback in improving test ordering in general practice. Scand J Prim Health Care 2003;21:219-23.

28. Eccles M, Steen N, Grimshaw J, et al. Effect of audit and feedback, and reminder messages on primary-care radiology referrals: a randomised trial. Lancet 2001;357:1406-9.

29. Szecsenyi J, Campbell S, Broge B, et al. Effectiveness of a qualityimprovement program in improving management of primary care practices. CMAJ 2011;183:E1326-33.

30. Shojania KG, Ranji SR, McDonald KM, et al. Effects of quality improvement strategies for type 2 diabetes on glycemic control: a meta-regression analysis. JAMA 2006;296:427-40.

31. Weiss KB, Wagner R. Performance measurement through audit, feedback, and profiling as tools for improving clinical care. Chest 2000;118:53S-8.

32. Gude WT, van der Veer SN, van Engen-Verheul MM, et al. Inside the black box of audit and feedback: a laboratory study to explore determinants of improvement target selection by healthcare professionals in cardiac rehabilitation. Stud Health Technol Inform 2015;216:424-8.

33. Ivers N, Jamtvedt G, Flottorp S, et al. Audit and feedback: effects on professional practice and healthcare outcomes. Cochrane Database Syst Rev 2012:Cd000259.

34. Chimeddamba O, Peeters A, Ayton D, et al. Implementation of clinical guidelines on diabetes and hypertension in urban Mongolia: a qualitative study of primary care providers' perspectives and experiences. Implement Sci 2015;10:112.

35. Mohr DC, Benzer JK, Young GJ. Provider workload and quality of care in primary care settings: moderating role of relational climate. Med Care 2013;51:108-14.

36. Feddock CA, Hoellein AR, Griffith $\mathrm{CH}$, et al. Are continuity clinic patients less satisfied when residents have a heavy inpatient workload? Eval Health Prof 2005;28:390-9.

37. Siegrist J, Shackelton R, Link C, et al. Work stress of primary care physicians in the US, UK and German health care systems. Soc Sci Med 2010;71:298-304

38. Tsiga E, Panagopoulou E, Sevdalis N, et al. The influence of time pressure on adherence to guidelines in primary care: an experimenta study. BMJ Open 2013;3:e002700.

39. Irving $\mathrm{G}$, Neves AL, Dambha-Miller $\mathrm{H}$, et al. International variations in primary care physician consultation time: a systematic review of 67 countries. BMJ Open 2017;7:e017902.

40. Mercer SW, Hasegawa H, Reilly D, et al. Length of consultations. Time and stress are limiting holistic care in Scotland. BMJ 2002;325:1241.

41. Mercer SW, Fitzpatrick B, Gourlay G, et al. More time for complex consultations in a high-deprivation practice is associated with increased patient enablement. Br J Gen Pract 2007;57:960-6.

42. Radwan M, Akbari Sari A, Rashidian A, et al. Appraising the methodological quality of the clinical practice guideline for diabetes 
mellitus using the AGREE II instrument: a methodological evaluation. JRSM Open 2017;8:205427041668267-8.

43. Burgers JS, Grol RP, Zaat JO, et al. Characteristics of effective clinical guidelines for general practice. Br J Gen Pract 2003;53:15-19.

44. Bero LA, Grilli R, Grimshaw JM, et al. Closing the gap between research and practice: an overview of systematic reviews of interventions to promote the implementation of research findings. The cochrane effective practice and organization of care review group. BMJ 1998;317:465-8.

45. Guyatt GH, Oxman AD, Vist GE, et al. GRADE: an emerging consensus on rating quality of evidence and strength of recommendations. BMJ 2008;336:924-6.

46. Brozek JL, Akl EA, Alonso-Coello P, et al. Grading quality of evidence and strength of recommendations in clinical practice guidelines. Part 1 of 3 . An overview of the GRADE approach and grading quality of evidence about interventions. Allergy 2009;64:669-77.

47. Alexander PE, Brito JP, Neumann I, et al. World Health Organization strong recommendations based on low-quality evidence (study quality) are frequent and often inconsistent with GRADE guidance. $J$ Clin Epidemiol 2016;72:98-106.

48. Widyahening IS, Wangge G, van der Graaf $Y$, et al. Adapting clinical guidelines in low-resources countries: a study on the guideline on the management and prevention of type 2 diabetes mellitus in Indonesia. J Eval Clin Pract 2017;23:121-7.

49. Home P, Haddad J, Latif ZA, et al. Comparison of national/regional diabetes guidelines for the management of blood glucose control in non-western countries. Diabetes Ther 2013;4:91-102.

50. Bennett WL, Odelola OA, Wilson LM, et al. Evaluation of guideline recommendations on oral medications for type 2 diabetes mellitus: a systematic review. Ann Intern Med 2012;156:27-36.

51. Stone MA, Wilkinson JC, Charpentier G, et al. Evaluation and comparison of guidelines for the management of people with type
2 diabetes from eight European countries. Diabetes Res Clin Pract 2010;87:252-60.

52. Harrison MB, Legare F, Graham ID, et al. Adapting clinical practice guidelines to local context and assessing barriers to their use. Can Med Assoc J 2010;182:E78-84.

53. Fervers B, Burgers JS, Voellinger R, et al. Guideline adaptation: an approach to enhance efficiency in guideline development and improve utilisation. BMJ Qual Saf 2011;20:228-36.

54. Burgers JS, Grol R, Klazinga NS, et al. Towards evidence-based clinical practice: an international survey of 18 clinical guideline programs. Int J Qual Health Care 2003;15:31-45.

55. Alonso-Coello P, Martínez García L, Carrasco JM, et al. The updating of clinical practice guidelines: insights from an international survey. Implement Sci 2011;6:107.

56. Vernooij RW, Sanabria AJ, Solà I, et al. Guidance for updating clinical practice guidelines: a systematic review of methodological handbooks. Implement Sci 2014;9:3.

57. Shekelle PG, Ortiz E, Rhodes S, et al. Validity of the agency for healthcare research and quality clinical practice guidelines: how quickly do guidelines become outdated? JAMA 2001;286:1461-7.

58. Shekelle P, Eccles MP, Grimshaw JM, et al. When should clinical guidelines be updated? BMJ 2001;323:155-7.

59. Martínez García L, Arévalo-Rodríguez I, Solà I, et al. Strategies for monitoring and updating clinical practice guidelines: a systematic review. Implement Sci 2012;7:109.

60. Becker M, Neugebauer EA, Eikermann M. Partial updating of clinical practice guidelines often makes more sense than full updating: a systematic review on methods and the development of an updating procedure. J Clin Epidemiol 2014;67:33-45.

61. Joosen MC, van Beurden KM, Terluin B, et al. Improving occupational physicians' adherence to a practice guideline: feasibility and impact of a tailored implementation strategy. BMC Med Educ 2015;15:82. 